\title{
Francisco de Paula Brito: política e imprensa
}

\section{Claudia Adriana Alves Caldeira}

Doutoranda em História na Universidade do Estado do Rio de Janeiro

Em seu ensaio intitulado Os protagonistas: da biografia, o historiador Philippe Levillain observa, a partir das teses acadêmicas produzidas na França nas décadas de 1960 e 1970, a retomada da história política e, paralelamente, um retorno dos estudos biográficos. ${ }^{1}$ Esses dois temas haviam sido eclipsados, na França, pela ascensão da História Social, e também pela influência marxista na produção historiográfica.

O retorno do indivíduo aos quadros de uma história política renovada acenou com novas possibilidades. Entre elas, a eleição de protagonistas que escapavam ao perfil dos grandes estadistas como fora comum nos trabalhos produzidos no século XIX.

A partir dessa perspectiva, o presente artigo tem como objeto parte da trajetória do editor, publicista, escritor e tradutor Francisco de Paula Brito, mais precisamente durante o período regencial. Buscou-se, aqui, destacar sua atuação à frente da folha $A$ Mulher do Simplicio ou a Fluminense exaltada, sua ligação à facção exaltada e a formação de uma rede de sociabilidade a partir de sua tipografia.

Entre prelos, impressos e política

Francisco de Paula Brito nasceu na cidade do Rio de Janeiro em dezembro de 1809. Mulato, de origem humilde e sem instrução formal, ingressou na oficina de aprendizes da Imprensa Nacional. Segundo Eunice Gondim, ali aprendeu seu ofício, empregando-se, em seguida, nas tipografias de Ogier e do Jornal do Commercio, permanecendo, nesta última, até a abertura de seu próprio estabelecimento. A maioria dos trabalhos sobre Paula Brito destacam sua atuação, como editor, à frente do jornal A Marmota Fluminense, no qual 
lançou jovens aspirantes a escritor como Machado de Assis. Outro aspecto, geralmente destacado, refere-se à Sociedade Petalógica, que reuniu políticos e literatos em sua livraria, formando uma espécie de confraria ou clube. A origem desse grupo, porém, remonta ao período regencial e às perseguições sofridas pela imprensa. Perseguições essas que não se restringiram, somente, aos redatores e periódicos, mas também às tipografias e aos impressores.

\section{A tipografia de Brito e $C$.}

Durante o conturbado período regencial, principalmente nos anos iniciais, a imprensa continuou a exercer importante papel na vida política. Além de eficiente ferramenta de crítica na esfera pública, passou a ser usada como um instrumento pedagógico, buscando informar ao público as propostas políticas pertinentes aos grupos que disputavam o poder. Desta forma se observa, na temática desenvolvida pelos jornais, referências que aludem às facções 'moderada", 'exaltada' e 'caramuru'.

Foi neste contexto de intensa agitação política e expansão da imprensa que Paula Brito adquiriu, de seu primo José Silviano de Almeida, em 1831, uma oficina de encadernação, localizada na Rua da Constituição, no. 51. Após um ano juntaria a ela os prelos comprados da tipografia de Ezequiel Corrêa dos Santos, redator da folha A Nova Luz Brasileira. Nascia assim a Tipografia de Brito e C., que em 1833 passaria a se chamar Tipografia Fluminense de Brito e C.

Inicialmente sua produção foi pequena, indicando um período de estruturação. Somente em 1833 Paula Brito parece se firmar como impressor. Neste ano, vários pasquins que faziam oposição ao governo saíram de seus prelos, entre eles O Evaristo, A Baboza, A Lima Surda, A Formiga.

Se o crescimento da imprensa acenava com boas possibilidades comerciais para os que quisessem se aventurar como impressor, implicava também riscos para os que exerciam essa atividade. O primeiro deles dizia respeito à legislação criminal do Império, que obrigava os impressores a divulgar os nomes dos redatores, ou assumirem a responsabilidade pelas publicações anônimas; o segundo se referia às invasões e atentados sofridos pelos estabelecimentos.

Em relação à legislação, o Código Criminal do Império, no capítulo I, artigo $7^{\circ}$., determinava o procedimento a ser seguido pelos impressores para se livrarem da responsabilidade do material impresso em seus estabelecimentos: 
$\int 1^{\circ}$. O impressor gravador ou litógrafo os quais ficarão isentos de responsabilidade mostrando por escrito obrigação de responsabilidade do editor. Sendo esta pessoa residente no Brasil, que esteja no gozo dos direitos políticos, salvo quando escrever em causa própria, caso em que não existe esta qualidade;

$\$ 2^{\circ}$. O editor que se obrigou, o qual ficará isento de responsabilidade, mostrando obrigação pela qual o autor, se responsabilize, tendo este as mesmas qualidades exigidas no editor, para escusar o autor. ${ }^{2}$

Um dos fatores que contribuíram para a formação de uma boa clientela na tipografia de Paula Brito foi o fato de não revelar a identidade daqueles que requisitavam seus serviços, assumindo a responsabilidade pelas publicações.

(...) diversos autores, redatores e responsáveis tinham jornais na minha oficina, e como não quisessem que seus nomes fossem publicados (o que também fazem os jornais da moderação) encarregaram-me de... assinar os anúncios que tivessem de ir para o Diário... ${ }^{3}$

O uso desse artifício fez com que as autoridades recorressem a outros métodos para penalizar os impressores: incitar a multidão contra essas tipografias. Esta experiência foi vivida por Paula Brito na noite de 5 de dezembro de 1833, quando teve de enfrentar a tentativa de invasão de seu estabelecimento. Sobre este episódio, Joaquim Manuel de Macedo declarou que não fora um ataque qualquer, pois os agressores "destruíram em grande parte tipografias em que se imprimiam gazetas da oposição..."4.

Segundo Brito, o motivo da invasão teria sido a publicação do jornal $O$ Restaurador. A folha, contendo oito páginas, circulou no dia 12 de novembro. O jornal foi acusado de defender o retorno de d. Pedro I. Em suas páginas, contudo, pode-se observar a crítica aos moderados, chegando a afirmar que o medo da restauração era apenas um artifício usado por esta facção na tentativa de se manter forte à frente do governo. Segundo Hélio Vianna, a autoria do jornal foi inicialmente atribuída a Paula Brito, passando, mais tarde, Evaristo da Veiga a responsabilizar João Batista de Queiroz por redigi-lo. 
Apesar dos riscos, Paula Brito conseguiu formar, a partir da clientela que ali se reunia para publicar suas folhas, um espaço de sociabilidade informal ${ }^{5}$ que mais tarde acabaria por se transformar na Sociedade Petalógica. Como o próprio impressor revelaria:

A Sociedade Petalógica ou de Petalogia, sociedade que, segundo seu título, não trata senão de petas, é um ajuntamento de pessoas, mais ou menos instruídas, que há cerca de 20 anos se reúnem n'um dos lugares mais belos e mais conhecidos desta Corte. Criada espontaneamente sem nome, no princípio o seu fim era todo político; mas como se mudam os tempos nós mudamos com eles - tempora mutantor et nos mutamur in ilis -, passou a ser unicamente recreativa ${ }^{6}$.

A ideia da tipografia como espaço de sociabilidade, porém, não se restringiu somente à experiência de Paula Brito, podendo ser observada na tipografia de Silva Porto, que durante o processo de Independência imprimia O Revérbero Constitucional Fluminense, servindo de ponto de encontro para Gonçalves Ledo, um de seus redatores, em 1822. As reuniões realizadas em seu estabelecimento teriam lhe valido críticas, sendo sua tipografia chamada de caverna de ciclopes ou cova de Trofonio. ${ }^{7}$

Em sua obra Memórias da Rua do Ouvidor, Joaquim Manuel de Macedo aponta a tipografia do Jornal do Commercio como um ambiente rico de segredos, um local de encontros secretos, no qual os eleitos eram admitidos mediante juramento, comparando-a à maçonaria.

\section{A Mulher do Simplicio on a Fluminense Exaltada}

Além da atividade de impressor, Paula Brito não limitou suas opiniões somente às conversas com o grupo de clientes e amigos que se reuniam em seu estabelecimento. Em 1832, lançava-se na arena pública com a folha $A$ Mulher do Simplicio ou a Fluminense exaltada.

Deve-se ressaltar que essa publicação recebeu pouca atenção nos estudos sobre história da imprensa. Nelson Werneck Sodré a menciona como um jornal faceto, sem efetuar maiores comentários. Para o historiador Helio Vianna, a folha faria parte de um grupo de jornais humorísticos, que classificou como 
família dos Simplicios. ${ }^{8}$ Recentemente Marcello Basile, em seu estudo sobre a formação da esfera pública na Corte, resgatou a importância desse jornal ao situá-lo nos debates políticos travados na imprensa como uma das folhas da facção 'exaltada', chamando a atenção para outra lacuna, a participação de Paula Brito neste grupo. ${ }^{9}$

O jornal A Mulher do Simplicio ou a Fluminense exaltada era totalmente redigido em versos, apresentando uma linguagem mais próxima à falada, como a literatura de cordel. Essa opção refletia também a experiência de Paula Brito como declamador de versos. Atividade que o aproximou, na juventude, de Evaristo da Veiga, que chegou a publicar algumas de suas composições. Outra característica apresentada pela folha era o fato de seu autor assiná-la como $A$ Redatora. A partir da leitura dessa folha, pode-se observar não só a postura política de Paula Brito, mas também anseios e esperanças de um homem de cor livre, em uma sociedade marcada pela escravidão e sua crítica à condição feminina. Antes de passar ao jornal, convém apresentar as facções para que se possa melhor compreender o debate político referente ao início dos anos trinta do período oitocentista.

Após a abdicação de d. Pedro, a facção moderada passou a coordenar a vida política no país. Esta facção teve por lema a razão e a ponderação, sendo vista por seus líderes como algo mais que uma concepção política. Apresentava-se mais próxima a uma visão de mundo racional e civilizada, que lhes possibilitava avaliar e proceder de forma ponderada e sábia diante de qualquer situação. ${ }^{10}$ A facção "exaltada", excluída do jogo político após a abdicação, adotava posições mais radicais, conclamando as massas à participação política. Defendia o federalismo, o direito de resistência dos povos preconizado por Locke e Rousseau, a república e a ampliação da cidadania ao maior número possível de pessoas, incluindo homens de cor livres e também as mulheres. Em relação a este último segmento, os 'exaltados' defendiam sua participação na vida publica, reconhecendo-lhe, inclusive, o direito ao voto.

Além dessas duas facções surgiu, depois, um terceiro grupo no cenário político da Regência, os 'caramurus'. Esse grupo era composto, principalmente, por portugueses que defendiam a monarquia e a centralização política, chegando alguns de seus participantes a defender o retorno de d. Pedro I.

O jornal de Paula Brito se apresentava em consonância com as idéias defendidas pelos 'exaltados' em relação à mulher. Em suas páginas a personagem, 
por ele criada, deveria servir de estímulo ao engajamento político de suas patrícias como modelo de mulher patriota que clamava pelo direito de manifestar sua opinião:

Frágil fez-me a natureza

mas, com firme opinião

é justo que a pátria escute

a voz do meu coração ${ }^{11}$

Como parte da imprensa 'exaltada', seu jornal atribuía à mulher também importante papel na esfera privada. Neste aspecto, destacava sua atuação como propagadora das ideias liberais no âmbito do lar:

\author{
Ensinai aos vossos filhos \\ esta excelente lição \\ sem pátria nós não podemos \\ gozar a constituição \\ Que sejais fiéis à pátria \\ e obedecei a lei \\ pois a primeira virtude \\ é a observância da lei \\ por não respeitar as leis \\ caiu o imperador \\ e cairá todo aquele \\ que dela for infrator ${ }^{12}$
}

Assim, na prática, restava às mulheres ensinarem aos filhos uma igualdade de que não desfrutavam, mas pela qual deveriam lutar.

A crítica à condição feminina, feita por Paula Brito, também pode ser observada nos folhetins que escreveu nas páginas do Jornal do Commercio em 1839. No conto O Enjeitado, por exemplo, deixa clara a sua posição em relação ao interesse financeiro, presente nos casamentos arranjados. Interesses que se sobrepunham ao péssimo caráter dos maridos: 
Mendonça teve vários filhos, entre os quais duas filhas, uma a mãe de nossa Emília, e outra mais velha, todos foram criados por seus pais, segundo os seus princípios, isto é, considerou-os a todos como seus escravos, e sobretudo a suas filhas, cujas vontades em coisa nenhuma foram consultadas. A mais velha (Júlia se chamava) casou-se aos treze anos. O Coronel Sousa tinha muito dinheiro, e tanto bastou para que Mendonça o julgasse um ótimo partido para sua filha. Tinha este quatro vezes a idade da noiva, estava carregado de filhos naturais de todas as cores... ${ }^{13}$

Paula Brito pertencia ao universo que a historiadora Mary Del Priore afirmou seguir a prática do casamento por amor, ${ }^{14}$ o que explicaria sua crítica à união por interesse, não deixando de observar, em seu conto, o tratamento dispensado às filhas, consideradas pelo personagem Mendonça como sua propriedade. Observa-se, ainda, a censura a um hábito então comum no país: a realização de casamentos de meninas, ainda muito jovens, com homens mais velhos. Prática essa que causou espanto e horror a alguns viajantes que por aqui estiveram e viram, neste costume, um desvio de conduta dos brasileiros.

Ao longo de sua trajetória Paula Brito publicou em seus jornais, e também editou trabalhos de diferentes autoras como a poetisa Benigna da Cunha, ${ }^{15}$ Nísia Floresta (Cartas a Minha Filha), Maria Benedita de Oliveira Barbosa (Zaíra Americana. Mostra as imensas vantagens que a sociedade inteira obtém da ilustração e da perfeita educação da mulher como mãe e esposa). A poetisa abolicionista Beatriz Francisca de Assis Brandão e Ana Luiza de Azevedo Castro tiveram trabalhos publicados nas páginas d'A Marmota Fluminense. A primeira contribuiu com poemas e traduções para a folha e a segunda teve seu romance D. Narcisa de Villar publicado em forma de folhetim. Com essa atitude contribuía ele para tornar a imprensa, através da literatura, um espaço mais democrático no qual, além das mulheres, lançaria também autores sem instrução formal e de origem semelhante à sua, como Teixeira e Sousa e Machado de Assis.

A cor: entre a Monarquia e a República

Outro aspecto que deve ser destacado na trajetória de Paula Brito é a questão racial que, no dizer de Celia Maria Marinho de Azevedo, despontou 
na imprensa em 1830; momento em que ele se lançou como impressor e publicista. Esta questão, sem dúvida, pesou em seu engajamento à facção exaltada, que na imprensa buscou chamar para suas fileiras os homens de cor livres, como A Nova Luz Brasileira:

As gentes de cor também têm parte no país, possuem propriedade, e são senhores; além disso, os homens sendo livres, honestos e honrados, e bons patriotas, são iguais perante a lei, e segundo a natureza e a constituição: logo quem insulta pela simples diferença de cor é inimigo da lei... ${ }^{16}$

Na política os 'exaltados', por defenderem uma cidadania mais ampla, não tardaram a ter sua imagem associada à chamada gente de cor. Nas páginas do Simplicio da Roça, o personagem, em tom de pilhéria, referia-se aos integrantes da facção como: "roídos pelo bicho da guiné que os faz apaixonados pela África." ${ }^{17}$

A trajetória de Paula Brito se entrelaça a esses acontecimentos, não somente por suas posições políticas, como 'exaltado', mas também por sua forte ligação com a imprensa e, principalmente, por ser um homem de cor em uma sociedade tida como preconceituosa:

Sou brasileiro, ainda homem de cor, a principal causa porque me faz guerra, mas que tanto tenho orgulho de ser, como os que tendo a cor mais clara que a minha se gloriam de ser brancos; falo dos negócios de meu país porque me dá esse direito a constituição de minha pátria. ${ }^{18}$

Durante a Regência, saíram de seus prelos folhas que, além de fazerem oposição ao governo, traziam em suas páginas o protesto dos chamados homens de cor diante da discriminação. Das fileiras 'caramurus' foram impressos, em sua tipografia, $A$ Baboza e $O$ Evaristo, que em meio aos ataques aos 'moderados' criticaram a exclusão de negros e mestiços livres. Uma das possíveis explicações para a inclusão desse tema nessas folhas seria a tentativa de reverter a imagem dos portugueses como inimigos dos brasileiros e, também, dos homens de cor. Esta manobra pode ser vista como uma forma de apaziguar os confrontos e chamar para suas fileiras este segmento. 
Importa ressaltar que os conflitos entre portugueses e brasileiros, segundo Ribeiro, estariam vinculados, inicialmente, à causa da Independência; porém, após sua concretização, revelariam raízes mais profundas que transcendiam o despertar da nacionalidade, apresentando um conteúdo político mais amplo. ${ }^{19}$ Para a autora esses conflitos tinham como pano de fundo a questão racial, refletida na disputa por mercado de trabalho, onde negros e mestiços viam-se preteridos em favor dos brancos portugueses.

Entre as folhas da facção 'exaltada', Paula Brito publicou O Sentinela da Liberdade no Rio de Janeiro, redigido pelo mulato Joaquim Cândido Meirelles. Porém o impressor é geralmente associado ao jornal O Mulato, ou Homem de Côr. Segundo Helio Vianna, este jornal poderia ter sido o primeiro órgão dos mestiços brasileiros, "caso obedecesse à orientação de Paula Brito." ${ }^{20}$ Contudo o autor aponta, em outra passagem, que é possível que o tipógrafo tenha influenciado na orientação do periódico por fazer parte da facção 'exaltada.' ${ }^{21}$ Embora não se possa atribuir sua redação a Paula Brito, a suspeita de Vianna tem fundamento se considerarmos a tipografia como espaço de sociabilidade.

Nas páginas d'A Mulher do Simplicio, em 1837, Paula Brito abordaria a questão racial, comparando à república a monarquia. Deve-se ressaltar que o impressor sempre defendeu a monarquia constitucional, diferindo nesse aspecto da maioria da facção 'exaltada' inclinada ao republicanismo.

Se as Rés publicas vizinhas, em quem somente falamos também sentem, mais ou menos, males que nos suportamos;

Se não tem o povo nelas, do que nós mais liberdade Se as classes não se nivelam Por uma lei de igualdade

Se homem de cor nos Estados Unidos (falemos francos) infeliz, não faz a barba, onde barbeiam-se os brancos; 
Bem claramente se vê
que nós os brasilianos
detestamos por princípios
governos republicanos ${ }^{22}$

Em seus versos apontava a existência, também nos países republicanos, de limitações. Em relação aos Estados Unidos reporta-se à condição dos homens de cor neste país, que mesmo conseguindo conquistar a liberdade tinham de enfrentar o preconceito e a segregação. Desta feita, seu discurso em relação ao modelo de governo se assentava em sua própria vivência. De que valeria para ele a república se os homens de cor permaneciam à margem? Em sua visão, os princípios da liberdade e da igualdade continuavam problemáticos como no Brasil. Assim sua defesa da monarquia frente à república tinha como base a questão da aceitação e assimilação dos negros na sociedade.

No início da década de 1840, após a vitória do movimento Maiorista promovido pelos liberais, e que foi apoiado por Paula Brito, a questão racial voltaria a aparecer:

Produz a maioridade

os desejados efeitos?

a prometida igualdade

na ordem de seus preceitos

os povos já tendo vão?

$(\ldots)$
Alguém o terá disposto
entre um povo tão mesclado,
a desprezar pelo rosto
o cidadão devotado
ao trono da nação?
(...) 


\begin{abstract}
Quem tiver merecimento, inda tendo a cor trigueira, encontrara valimento, ou continua a manqueira de amanhã sim, hoje não. ${ }^{23}$
\end{abstract}

Seu discurso neste momento, além das marcas do desânimo, também se reporta a sua condição de homem de cor, indagando, em seus versos, se realmente alguma coisa mudaria com a Maioridade. Mostrava-se temeroso de que mais uma vez a balança das oportunidades continuasse a pender de forma desigual, desconsiderando o mérito dos cidadãos.

Pode-se deduzir que para um indivíduo como Paula Brito, em busca de ascensão social, ter a seu favor alguns políticos possibilitava-lhe maiores oportunidades. Neste sentido, a amizade com alguns membros do Partido Conservador ajuda a compreender melhor sua guinada em direção a este partido.

Nas páginas de seu jornal, dois políticos foram homenageados em 1841: Euzébio de Queiroz e Paulino José Soares de Souza, ambos conservadores. Chama atenção o longo agradecimento dedicado a este último, no qual se pode observar um relacionamento mais intimo, chamando-o publicamente de mecenas, chegando a dizer que sua sorte teria sido outra se o tivesse conhecido antes:

Longe eu fora, senhor, se não temera

Teu melindre ofender, eu te conheço!

Mas perdoa que um peito, grato sempre,

Que um cidadão, quer dar-te nada pode,

Digno talvez de mais propícia sorte,

Se mais cedo te houvera por mecenas... ${ }^{24}$

Neste mesmo ano, o amigo e protegido de Paula Brito, o também mulato Teixeira e Souza, dedica a obra Cânticos líricos ao futuro visconde do Uruguai. Deve-se considerar que as dedicatórias consistiam em uma estratégia para atrair a proteção daquele que fora homenageado. Não por acaso, Paulino José Soares de Sousa figura na lista de subscritores com 41 exemplares. Um pouco mais do que o dobro do que fora adquirido pelo segundo maior subscritor, o médico Joaquim Candido Meireles (20 exemplares). 
Deve-se destacar que a fama de Paula Brito se consolidaria a partir de 1850, atuando como incentivador do Romantismo no Brasil, movimento esse que segundo o historiador Bernardo Ricupero manteve ligações com o projeto político saquarema. O autor ressalta, em especial, a proximidade de políticos conservadores com a Revista Guanabara. ${ }^{25}$

Os versos publicados por Paula Brito, em homenagem a Paulino José Soares de Sousa, revelam que a proteção oferecida pelo político não se restringiu somente às letras, incluindo em seu agradecimento referências a pedidos atendidos por ele:

Foi desde então senhor que me outorgaste

Sinceras provas de grandeza d'alma

Que para o bem fazer os céus te dera!

Ali, de um triste pai a infausta sorte

Por mim tu melhoraste, e a pobre esposa

Deu aos filhos o pão que lhe enviaste,

E o único que tem! ${ }^{26}$

Recorria também Paula Brito a outro integrante do partido conservador, Euzébio de Queiroz, sendo este citado por Coaracy como integrante da Sociedade Petalógica ${ }^{27}$. Além dos versos que lhe foram dedicados em A Mulher do Simplicio, em 1841, outro relato afirma o grau de intimidade entre eles:

Um dia uma mulher do povo, cujo filho fora recrutado, sabendo que Paula Brito era amigo do ministro de Estado, procurou-o e pediu-lhe que intercedesse em favor do filho. Paula Brito lembrava das palavras do amigo, mas... Pensou e, afinal, deu à mulher uma petição em versos para o ministro na condição de jamais revelar o nome do autor. Entregue o papel, Euzébio de Queiroz reconheceu o estilo e disse à suplicante que só mandaria soltar o recruta se ela lhe falasse a verdade e dissesse quem era o autor dos versos. Em grandes dificuldades, a mulher pediu licença ao ministro e saiu para falar com Paula Brito. Foi então que Euzébio de Queiroz seguiu-a e encontrou-a na tipografia discutindo com o famoso jornalista e tipógrafo. Foi 
quando Euzébio disse a Paula Brito: - Teu coração não é maior que o meu. Senhora, vá buscar o seu filho... ${ }^{28}$

A admiração de Paula Brito por estes políticos por certo influenciou sua adesão aos conservadores.

Como se pode observar, a figura de Paula Brito não se constrói a partir do Segundo Reinado. O período regencial é de grande importância para maior conhecimento de suas atividades, momento de seu despontar, dos primeiros passos à frente de sua própria tipografia e do início da formação de uma rede de relações que o acompanharia pelo resto de sua vida. A partir das páginas d'A Mulher do Simplicio, pode-se observar questões referentes à condição feminina e também a sua experiência como homem de cor. Deve-se destacar sua opção de redigir um jornal ocultando sua identidade masculina, pois como observou Daniel Roche, em Cultura das aparências, durante o século XVIII, era comum homens escreverem sob pseudônimo feminino. Esta forma de se ocultar revelaria uma estratégia para se colocar na arena pública, de forma mais livre, ao assumir a identidade de outro sexo. ${ }^{29}$ 


\section{Notas e Referências}

1 Philippe LEVILLAIN. “Os protagonistas: da biografia”. In: René RÉMOND. Por uma história política. Rio de Janeiro: FGV, 2003, p. 141.

2 José Henrique PIERANGELI. Códigos Penais do Brasil. São Paulo: Revista dos Tribunais, 2004, p. 237 - 238.

3 O Carioca, n'. 12, 21/01/1834.

4 Joaquim Manuel de MACEDO. Anno Biographico Brazileiro. Rio de Janeiro: Typographia e Litographia do Imperial Instituto Artístico, 1873, vol. 3, p. 547.

5 Por associações informais entendem-se aquelas que se formam sem estatutos e não possuem uma hierarquia, desenvolvendo-se em espaços como a rua e o ambiente de trabalho. Para a análise dos tipos de sociabilidades desenvolvidas nos espaços físicos que compõem a esfera pública, ver Marco MOREL. As transformações dos espaços públicos: imprensa, atores políticos e sociabilidades na Cidade Imperial (1820-1840). São Paulo: Hucitec, 2005, p. 109.

6 A Marmota Fluminense, no. 380, 5/07/1853.

7 Cybelle de IPANEMA e Marcello IPANEMA. Silva Porto: Livreiro na Corte de D. João, editor na Independência. Rio de Janeiro: Capivara Editora, 2007, p. 101.

8 Helio VIANNA indica em sua obra Contribuição ao estudo da imprensa ter escrito um artigo sobre os Símplicios, mas apesar das indicações não conseguimos localizá-lo, p. 208.

9 Marcello Otávio Néri de Campos BASILE. O Império em construção: Projetos de Brasil e ação política na Corte regencial. Tese de Doutorado. Rio de Janeiro: IFCS-UFRJ, 2004.

10 Marco MOREL. O Período Regencial (1831- 1840). Rio de Janeiro: Jorge Zahar, 2003, p. 35.

11 A Mulher do Simplicio, no. 3, 10/03/1832.

12 Idem.

13 Francisco de Paula BRITO. "O Enjeitado”. In: Barbosa LIMA SOBRINHO. Os precursores do Conto brasileiro. Rio de Janeiro: Civilização Brasileira, 1960, p. 208-209.

14 Mary DEL PRIORE. História do casamento e do amor no Brasil. São Paulo: Contexto, 2005, p. 159. 
15 Teve alguns de seus versos publicados n'A Mulher do Simplicio ou a Fluminense exaltada.

16 Nova Luz Brasileira, nº. 26, 9/03/1830. Apud Marcello Otávio Néri de Campos BASILE. O Império em construção: Projetos de Brasil e ação política na Corte regencial. Tese de Doutorado. Rio de Janeiro: IFCS-UFRJ, 2004, p. 153-201.

17 O Simplicio da Roça, nº. 3, 22/11/1831.

18 O Carioca, nº. 12, 21/01/1834.

19 Gladys Sabina RIBEIRO. Liberdade em Construção. Rio de Janeiro: RelumeDumará, 2002, p. 247.

20 Helio VIANNA. Contribuição à história da imprensa brasileira. Rio de Janeiro: Imprensa Nacional, 1945, p. 219.

21 Idem, ibidem, p. 219.

22 A Mulher do Simplicio, no. 8, 24/03/1937.

23 Ibidem, n'. 66, 25/12/1840.

24 Ibidem, $\mathrm{n}^{\circ}$. 71, 25/12/ 1841.

25 RICUPERO, Bernardo. O Romantismo e a ideia de nação no Brasil. São Paulo: Martins Fontes, 2004, p. 100.

26 A Mulher do Simplicio, no. 71, 25/12/1841.

27 Vivaldo COARACY. Memórias da cidade do Rio de Janeiro. Belo Horizonte: Itatiaia; São Paulo: Edusp, 1988, p. 99.

28 Teixeira SOARES. "No tempo de Machado de Assis". In: Jornal do Commercio, 12/06/1939.

29 Daniel ROCHE. Cultura das aparências. Apud PALLARES-BURKE, Maria Lúcia. In: Nísia Floresta, o Carapuceiro e outros ensaios de tradução cultural. São Paulo: Hucitec, 1996, p. 99. 